\title{
Biomechanical Analysis of Sagittal Plane Pin Placement Configurations for Pediatric Supracondylar Humerus Fractures
}

\author{
Witit Pothong ${ }^{1}$, Phichayut Phinyo ${ }^{2,3} \mathbb{0}$, Yuddhasert Sirirungruangsarn ${ }^{1}$, Kriengkrai Nabudda ${ }^{4}$, \\ Nattamon Wongba ${ }^{5}$, Chatchawarl Sarntipiphat ${ }^{5}$ and Dumnoensun Pruksakorn $1,6,7, *$ \\ 1 Department of Orthopedics, Faculty of Medicine, Chiang Mai University, Chiang Mai 50200, Thailand; \\ wertybooky@gmail.com (W.P.); yuddaser@@hotmail.com (Y.S.) \\ 2 Department of Family Medicine, Faculty of Medicine, Chiang Mai University, Chiang Mai 50200, Thailand; \\ phichayutphinyo@gmail.com \\ 3 Center for Clinical Epidemiology and Clinical Statistics, Faculty of Medicine, Chiang Mai University, \\ Chiang Mai 50200, Thailand \\ 4 Research Center for Orthopedics Biomechanics, Khon Kaen University, Khon Kaen 40002, Thailand; \\ kriang_36@hotmail.com \\ 5 Department of Orthopedics, Faculty of Medicine, Khon Kaen University, Khon Kaen 40002, Thailand; \\ mo_nattan@hotmail.com (N.W.); chat-sarn@hotmail.com (C.S.) \\ 6 Musculoskeletal Science and Translational Research Center, Chiang Mai University, \\ Chiang Mai 50200, Thailand \\ 7 Biomedical Engineering Institute, Chiang Mai University, Chiang Mai 50200, Thailand \\ * Correspondence: dumnoensun.p@cmu.ac.th; Tel.: +66-53-935-540
}

\section{check for} updates

Citation: Pothong, W.; Phinyo, P.; Sirirungruangsarn, Y.; Nabudda, K.; Wongba, N.; Sarntipiphat, C.; Pruksakorn, D. Biomechanical Analysis of Sagittal Plane Pin Placement Configurations for Pediatric Supracondylar Humerus Fractures. Appl. Sci. 2021, 11, 3447. https://doi.org/10.3390/app11083447

Academic Editors: Frank Seehaus and Ana Paula Betencourt Martins Amaro

Received: 18 February 2021

Accepted: 6 April 2021

Published: 12 April 2021

Publisher's Note: MDPI stays neutral with regard to jurisdictional claims in published maps and institutional affiliations.

Copyright: (c) 2021 by the authors. Licensee MDPI, Basel, Switzerland. This article is an open access article distributed under the terms and conditions of the Creative Commons Attribution (CC BY) license (https:// creativecommons.org/licenses/by/ $4.0 /)$.

\begin{abstract}
Anterior to posterior (AP) pinning is the recommended sagittal pin configuration in divergent lateral entry coronal pinning of pediatrics supracondylar fractures. However, there was still a lack of evidence regarding alternative sagittal pins configurations. We aimed to compare the construct stiffness of alternative sagittal pin configurations by using synthetic bone models. Sixty synthetic pediatric humeri were osteotomized to create a supracondylar fracture. After the fracture reduction, all specimens were fixed in the coronal plane with divergent lateral entry pin configurations in four different patterns in the sagittal plane: AP, crossed, divergent and parallel sagittal pin configuration. Each configuration was tested with five loading patterns. The AP sagittal pin had significantly lower construct stiffness than the divergent $(p=0.003)$ and the parallel sagittal pin configuration $(p=0.005)$ in external rotation loading tests. The divergent sagittal pin had the highest construct stiffness in extension, valgus, and external rotation loads, but the parallel sagittal pin had lower construct stiffness under extension load than the divergent and crossed sagittal pin configurations. The divergent sagittal pin configuration provides greater construct stiffness than other sagittal pin configurations due to the maximal pin spreading distance at the fracture site and the pin angle lock mechanism.
\end{abstract}

Keywords: supracondylar humeral fracture; biomechanical study; sagittal pinning; Kirschner wires

\section{Introduction}

Supracondylar fractures of the distal humerus are the most common fractures in children, with the peak incidence at age 4-7 years [1]. Many treatment methods have been described, e.g., closed reduction with a long-arm cast, skin traction, axial skeletal traction, and flexible nailing. In the 1940s, publication on closed reduction and percutaneous pinning [2] described the currently preferred surgical treatment for displaced supracondylar fractures [3-6]. The crossed medial-lateral and lateral entry pin configuration in the coronal plane have been favored as an effective pinning technique [7-14]. Biomechanical studies have reported that crossed medial-lateral pins provide greater torsional stiffness than lateral entry pin fixation [15-18] but no clinical difference in treatment outcome [19-22]. We considered two pins with divergent lateral entry to be the most appropriate configuration 
in the coronal plane because the crossed medial-lateral pin configuration is associated with a higher risk of iatrogenic ulnar nerve injury $[6,7,9,21,23]$.

In contrast to the coronal plane, the construct stiffness of each pin configuration in the sagittal plane has not been extensively evaluated, with few biomechanical or clinical studies on the issue. Anterior to posterior (AP) pinning is currently the most common recommendation for sagittal pin configuration. Ariño suggested using two Kirschner wires (K-wire) with either parallel or crossed pin configuration in both the coronal and sagittal plains [24]. Kallio and Skaggs suggested the appropriate inclination for sagittal pin insertion is from the anterior part of the distal fragment to the posterior part of the diaphyseal cortex $[25,26]$. Recently, Wallace designed a biomechanical torsion test for sagittal pin configurations [27]. However, no statistically significant difference in torsional stiffness among the three types of sagittal pin configurations was found in the study.

This study aimed to use biomechanical tests to compare the construct stiffness of various types of sagittal pin configurations for pediatrics supracondylar fractures using controlled fixation with two divergent lateral entry pin configurations in the coronal plane under axial torsion and displacement loads.

\section{Materials and Methods}

\subsection{Materials}

We conducted a biomechanical analysis of sagittal pin placement configurations for pediatric supracondylar humerus fractures. The research ethics committee of the Faculty of Medicine, Chiang Mai University, approved the study protocol (ORT 2562 06622). Sixty Sawbones pediatric synthetic humeri (Sawbones model \#1052, Pacific Research Laboratories, Vashon Island, WA, USA) were obtained using the same model in previous pediatrics supracondylar humerus fracture biomechanics studies $[27,28]$. These synthetic humeri are made of a rigid foam shell with inner cancellous material and are anatomically correct pediatric bone dimensions.

\subsection{Methods}

We controlled coronal plane pinning with two divergent lateral entry pin configurations following the technique of Hamdi [29]. Different pin placement configurations in the sagittal plane were evaluated for feasibility, given the limited area/size of pediatric bones. All configurations were bicortical medial and lateral cortex fixation. We established zones of pin entry and exit using the transverse diaphyseal diameter of the humeral shaft in the sagittal plane as reference. We first divided the anterior and posterior with an anatomical axis line, after which we drew a vertical line separating the cortical bone and the intramedullary canal. Then we designated four zones where pins would penetrate the bone cortex: zone $1=$ the anterior diaphyseal cortex, zone $2=$ the anterior diaphyseal medullary canal, zone $3=$ the posterior diaphyseal medullary canal, and zone $4=$ the posterior diaphyseal cortex (Figure 1). In each case, both pins were started from the lateral part of the distal fragment to the medial diaphyseal cortex. Pin trajectories were labeled numerically by entry and exit zone, e.g., 2-3 represents pin entry at the lateral part of the distal fragment (zone 2) and exit at the medial diaphyseal cortex (zone 3). In the coronal plane: the first pin was proximal and was parallel to the lateral metaphyseal flare of the humeral cortex; the second pin was distal and crossed the fracture site at the medial edge of the coronoid fossa. In the sagittal plane: the combined pin configuration designation listed the proximal pin trajectory first and distal pin trajectory second. For example, if the first proximal pin trajectory was $2-2$ and the second distal pin trajectory was 1-1, the pin configuration was represented as [2-2,1-1]. Finally, four different pin configurations were chosen for study: the AP sagittal pin configuration [2-3,1-3] (currently the standard recommendation), the crossed sagittal pin configuration [2-4,4-2], the divergent sagittal pin configuration [3-3,3-1], and parallel sagittal pin configuration [3-3,2-2]. 


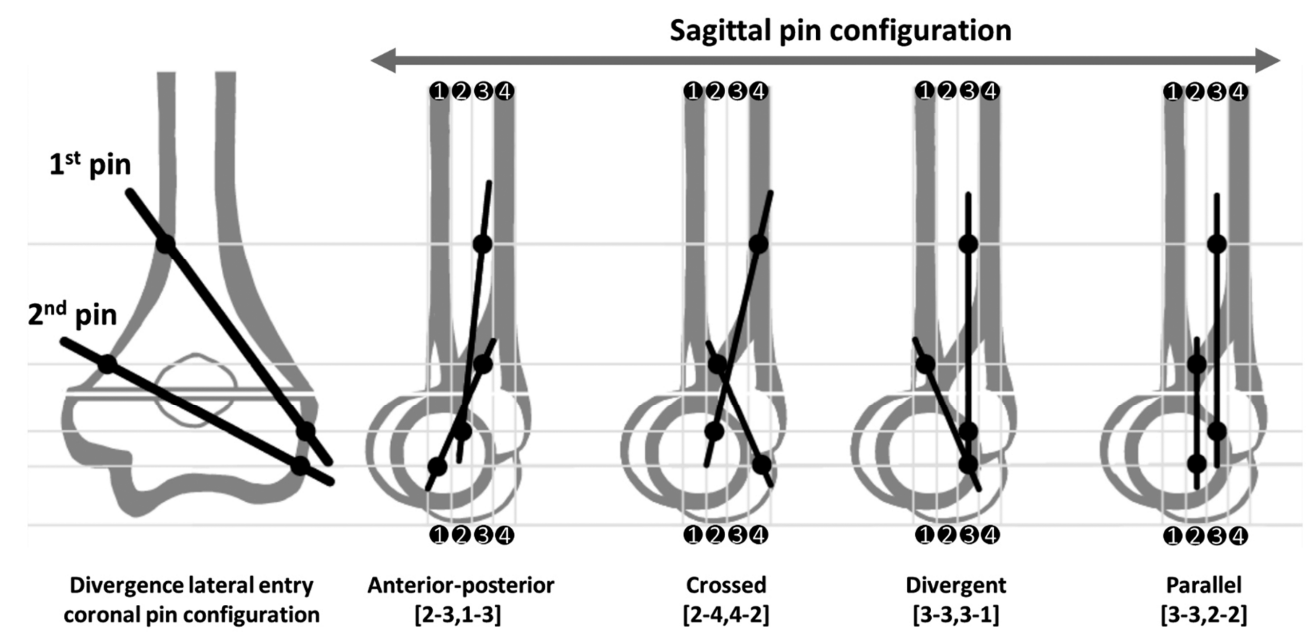

Figure 1. Schematic showing the orientation of the four sagittal pin configurations in the controlled divergence lateral entry coronal pin configurations. The black dots represent the location of pin penetration through the bone cortex.

Four pin targeting guides were created from an epoxy resin casting to provide pin placement consistency and reproducibility. The specimens were securely encased in the epoxy mold and $1.5 \mathrm{~mm}$ holes were predrilled using the pin targeting guide. Transverse osteotomies were made at the level of the epicondyle (mid olecranon fossa) perpendicular to the anatomic axis of the humerus ( $28 \mathrm{~mm}$ from the distal end of the trochlea humerus) with a 0.5 -mm cutting blade and the custom-built guide cutting. After fracture reduction, two pieces of $1.6 \mathrm{~mm}$ diameter Kirchner wire were inserted through the predrilled in the center of each of the four zones. After pinning, a fluoroscopic evaluation was accomplished to confirm the placement of all wires. Bone specimens underwent axial torsion and displacement load tests using an Instron ElectroPuls ${ }^{\mathrm{TM}}$ E10000 (Instron, Norwood, MA, USA).

In external and internal torsion tests, we created an epoxy resin mold jig system consisting of outer and inner parts (Figure 2). The outer mold jig was attached permanently to the testing machine at the center of rotation of the long anatomical axis of the humerus to ensure that the position did not vary between specimens. The inner part could be moved into and out of the outer mold jig. After the bone specimen was inserted into the proximal and distal parts of the inner mold jig, it was mounted vertically on an outer jig and secured tightly with multiple bolts and nuts. Loads were applied to the proximal part of the bone by an actuator. The actuator allowed $0-25^{\circ}$ of internal and external rotation, and samples were tested at a rate of 0.5 degrees/second. Torque ( $\mathrm{Nm} /$ degrees) and degrees of rotation were recorded. Based on previous studies, rotational testing beyond $25-30^{\circ}$ resulted in a plastic deformation or failure of the construct $[16,18]$. Thus, in this study, we limited the degree for rotational testing at 25 degrees.

For extension, varus, and valgus displacement tests, the proximal part of the specimen was secured in a horizontal cylindrical metal tube (Figure 3). The anatomical axis of the humerus was set at the center of the cylindrical tube for all specimens. Load displacement was applied by the actuator of the machine via the $8 \mathrm{~mm}$ diameter cylindrical rod at a level $1 \mathrm{~cm}$ distal to the fracture site. The load was applied at the distal part, increasing displacement from 0 to $7 \mathrm{~mm}$ at a rate of $0.5 \mathrm{~mm} /$ second. Displacement $(\mathrm{mm})$ and force $(\mathrm{N} / \mathrm{mm})$ were recorded. We used a maximal translational displacement of $7 \mathrm{~mm}$ as this point was the maximal point for all previous biomechanical analyses for the construct stiffness of supracondylar fracture. 


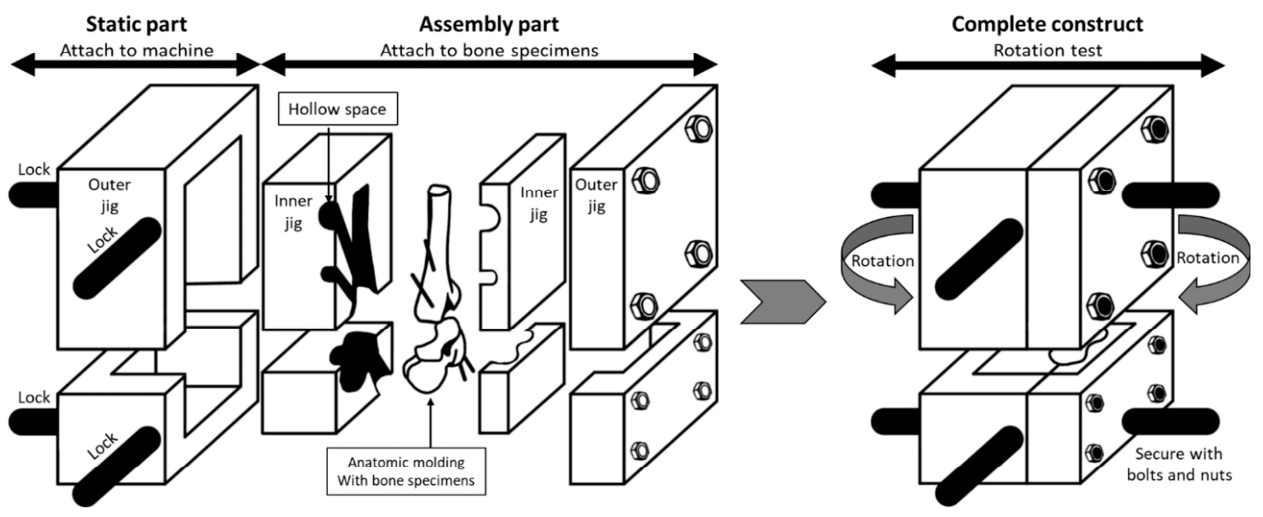

Figure 2. Schematic presentation of the two layers of the axial torsional mold jig. The outer layer was statically attached to the testing machine. The inner layer containing the bone specimen could be moved into and out of the assembly. The portion of the pins extending beyond the bone was accommodated in hollow spaces of the mold jig without impingement. All constructs were secured tightly with multiple bolts and nuts.

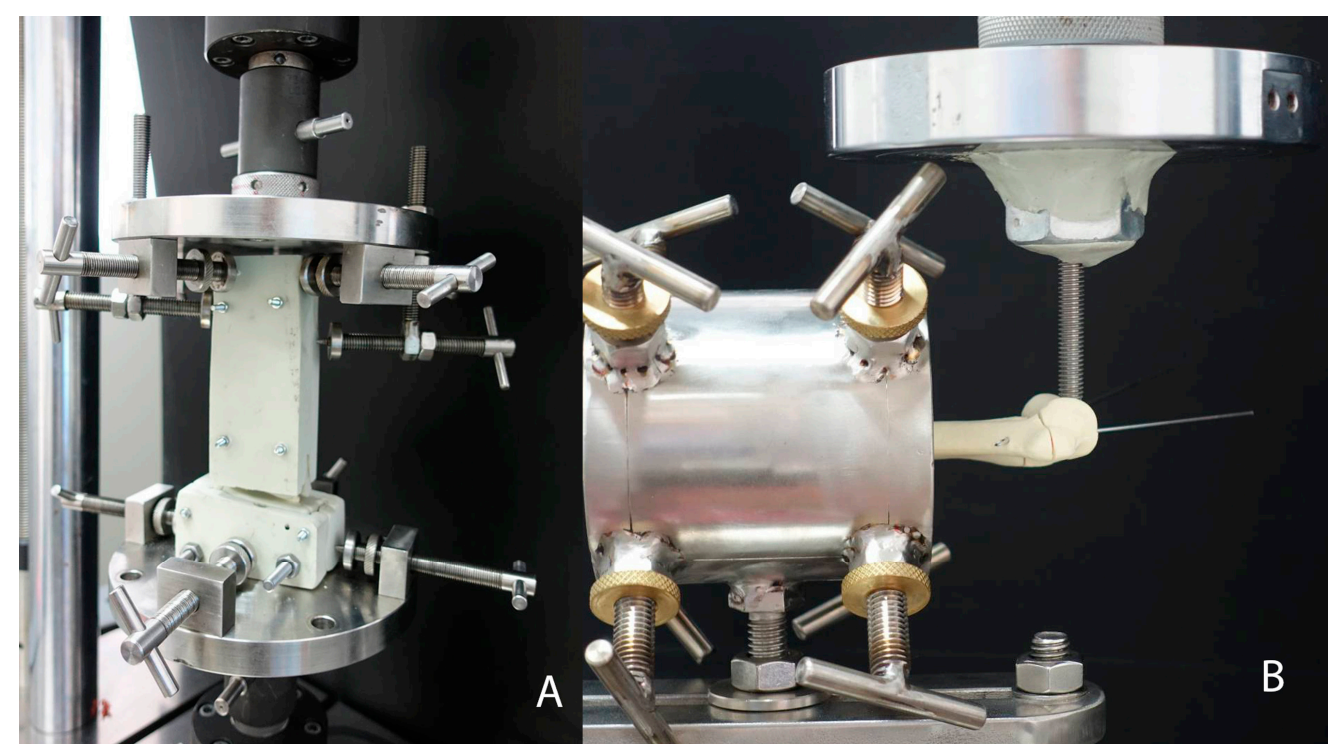

Figure 3. A specimen mounted in the testing machine: (A) axial torsion test (internal and external rotation) using the custom epoxy resin fixation jig and (B) load displacement test (extension, valgus and varus) using the fixed metal tube.

A total of 60 humeri were prepared in four different pin configurations (15 specimens per configuration). Three specimens of each configuration were used in each loading test. Specimens were tested only once to avoid potential measurement errors due to bone destruction during the previous experiment.

\subsection{Statistical Analysis}

One-way analysis of variance with repeated measures was used to compare the construct stiffness of the four different pin configurations for each of the five modes of applied force. Statistical significance was set at $p<0.05$. Post hoc Bonferroni comparison was conducted to determine the specific difference between the pin configurations in cases where one-way analysis of variance detected differences. Data analysis was conducted using STATA version 16 (StataCorp, College Station, TX, USA).

\section{Results}

There were no permanent construct failures due to bone specimen fracture, pin deformation, or loss of fixation in any loading conditions. 
Construct stiffness (Figure 4) was calculated from the slope of the load-displacement curve that best fit the data with the linear portion between 2 and $7 \mathrm{~mm}$ of the loaddisplacement curve and torsional stiffness was measured between 5 and 25 degrees of the load-displacement curve.
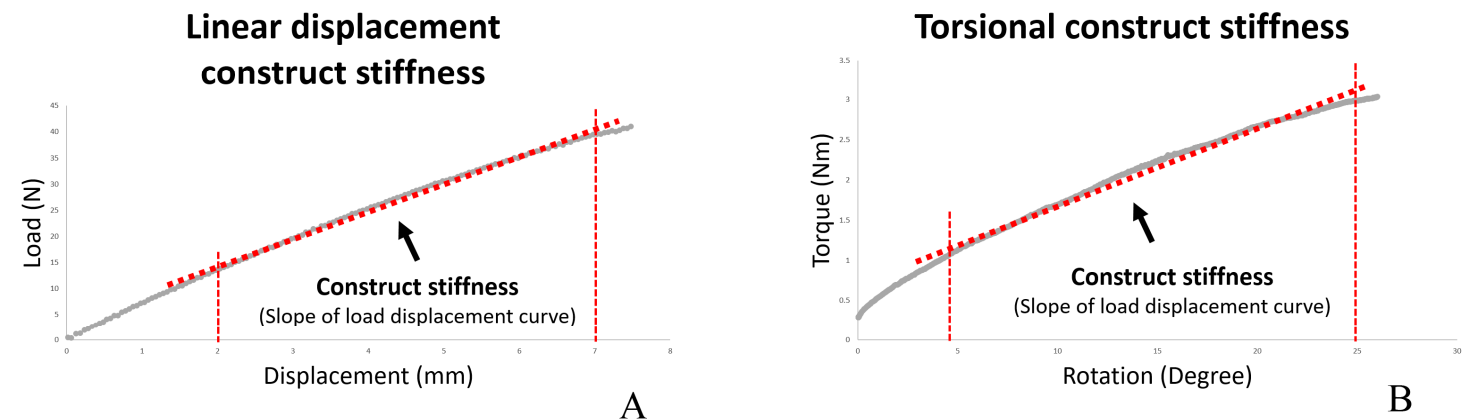

Figure 4. Load-displacement curve generated during sagittal pin configurations stiffness assessment. The construct stiffness was calculated from the slope of the load-displacement curve best fitting the data between 2 and $7 \mathrm{~mm}$ of displacement (A). Torsional stiffness was measured between 5 and 25 degrees of rotation (B).

Figures 5 and 6 show a torsional and linear load-displacement curve and slope loaddisplacement curve (construct stiffness) of all 4 pins configurations under external rotation, internal rotation, extension, valgus, and varus load.

External Rotation

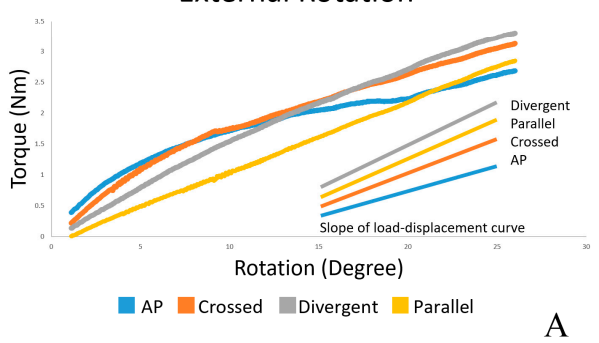

Internal Rotation

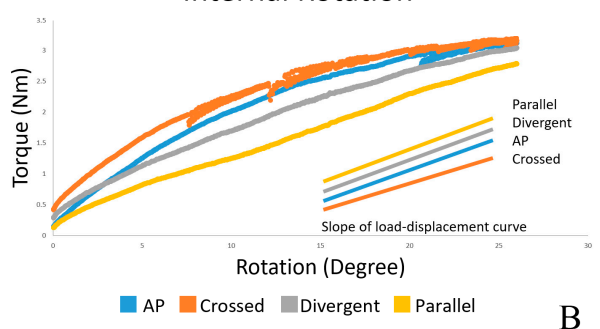

Figure 5. Comparison between the torsional load-displacement curve and slope of the load-displacement curve between different sagittal pin configuration in external rotation load (A) and internal rotation load (B).

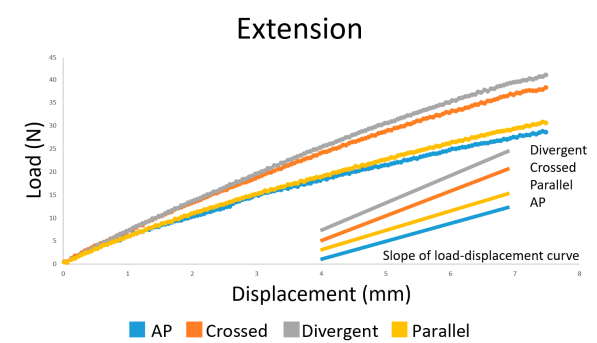

A

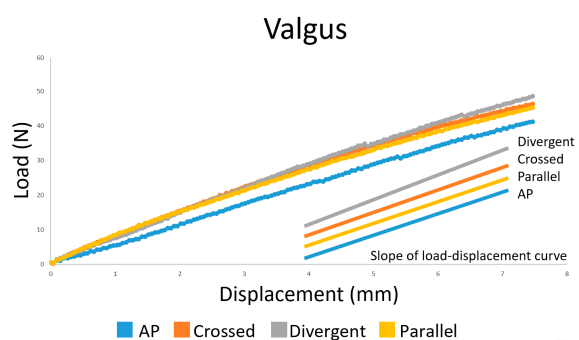

B

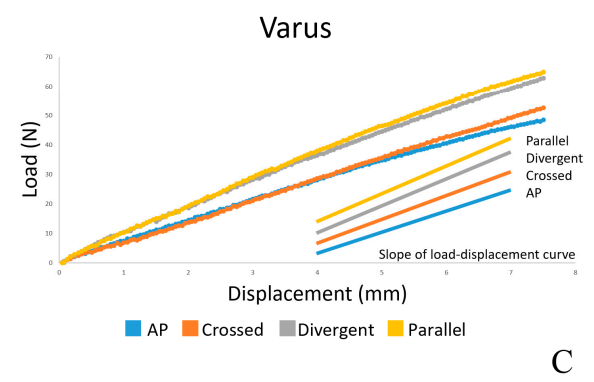

Figure 6. Comparison between linear load-displacement curve and slope of the straight line of different sagittal pin configuration in extension load (A) and valgus load (B) and varus load (C). 
There was no statistically significant difference among the four-pin configurations in extension, valgus, varus, and internal rotation loading (Table 1).

Table 1. Comparison of construct stiffness of different pin configurations in the sagittal plane.

\begin{tabular}{cccccc}
\hline Loading & AP & Crossed & Divergent & Parallel & ANOVA $\boldsymbol{p}$-Values \\
\cline { 2 - 5 } Condition & Mean \pm SD & Mean \pm SD & Mean \pm SD & Mean \pm SD & 0.066 \\
\hline Extension (N/mm) & $3.38 \pm 1.25$ & $4.73 \pm 0.79$ & $5.20 \pm 0.45$ & $3.68 \pm 0.21$ & 0.726 \\
Valgus (N/mm) & $5.54 \pm 0.72$ & $5.79 \pm 0.75$ & $6.21 \pm 0.78$ & $5.63 \pm 0.77$ & 0.132 \\
$\quad$ Varus (N/mm) & $6.36 \pm 1.64$ & $7.13 \pm 0.97$ & $8.01 \pm 0.57$ & $8.46 \pm 0.40$ & 0.134 \\
Internal rotation & $0.085 \pm 0.006$ & $0.073 \pm 0.006$ & $0.093 \pm 0.020$ & $0.098 \pm 0.010$ & 0.002 \\
$\quad(\mathrm{Nm} /$ deg) & & & & \\
External rotation & $0.063 \pm 0.008$ & $0.093 \pm 0.017$ & $0.120 \pm 0.012$ & $0.115 \pm 0.010$ & \\
$\quad(\mathrm{Nm} /$ deg) & & & & & \\
\hline
\end{tabular}

Abbreviations: AP, anterior to posterior pinning; ANOVA, analysis of variance.

For external rotation loading, anterior to posterior pinning gave the lowest construct stiffness $(0.063 \pm 0.008 \mathrm{Nm} / \mathrm{deg})$. This was significantly lower than for both divergent pinning $(0.120 \pm 0.012 \mathrm{Nm} / \mathrm{deg})$ and parallel pinning $(0.115 \pm 0.010 \mathrm{Nm} / \mathrm{deg})(p=0.003$ and $p=0.005$, respectively) (Table 2 ).

Table 2. Post hoc comparison of external rotation loading of different pin configurations.

\begin{tabular}{cccc}
\hline $\begin{array}{c}\text { External Rotation } \\
(\mathbf{N m} / \mathbf{d e g})\end{array}$ & AP & Crossed & Divergent \\
\hline Crossed & $p=0.096$ & & \\
Divergence & $p=\mathbf{0 . 0 0 3}$ & $p=0.165$ & $p=1.000$ \\
Parallel & $p=\mathbf{0 . 0 0 5}$ & $p=0.359$ & \\
\hline
\end{tabular}

Abbreviations: AP, anterior to posterior pinning; ANOVA, analysis of variance. Statistically significant figures are shown in bold figures.

\section{Discussion}

Adequate fixation stability is the key measure of success in the treatment of displaced pediatric supracondylar fractures. Closed reduction and percutaneous pinning is a standard technique for fixation, especially for Gartland type 2 and type 3 fractures $[6,30]$. Low construct stiffness is an important factor in the loss of fracture reduction. Many previous studies have discussed construct stiffness in the coronal pin configuration. The divergent lateral entry pin technique has been recommended in many institutes because of the lower risk of iatrogenic ulnar nerve injury than the medial-lateral crossed pin technique $[7,31]$. In contrast, there have been few studies in biomechanical and clinical evidence about the sagittal pin configuration. Our study aimed to biomechanically evaluate which of the sagittal pin configuration has the strongest construct stiffness in two controlled divergence lateral entry coronal pin configurations.

The sagittal pin configuration in this study was based on two considerations: first, limitations on the use of K-wire in small pediatric bones, and second, the K-wire must penetrate only the lateral and medial cortex of the bones. K-wire inserted into the medullary canal must travel without cutting through the bone cortex. For each test, a newly synthetic specimen was used instead of reused specimen because the initial procedure could potentially have damaged the outer cortical and inner cancellous structure of the synthetic bone after previous testing and thus destroyed or changed its material construction.

This study investigated three interesting areas. The first area is the weakness of the AP sagittal pin configuration. Although AP is the standard recommendation for sagittal pin configuration, there are many alternative pin configurations for fixation, which have not yet been thoroughly evaluated. The present study found that the AP sagittal pin configuration had the lowest construct stiffness under many load types. We used previous studies associated with coronal pin configuration to explain the lack of this construct stiffness. 
Kallio suggested that the pins cross each other in the lateral entry pin configuration at the fracture site level [25], resulting in horizontal malrotation and the development of cubitus varus. Ziont showed that the two coronal lateral entry pinning, which crosses at the fracture site, has very low construct stiffness [18]. Sankar et al. suggested that loss of reduction occurs when the pins are too close to each other at the fracture site level [20]. We assumed that the construct weakness in the coronal plane is the result of two pins starting from the same side and crossing near the fracture site level. We applied this assumption to the AP sagittal pin configuration, where two pins also start from the same anterior side and cross near the fracture site, which might explain why the AP sagittal pin configuration has lower construct stiffness than the other sagittal pin configurations.

The second area is the divergent sagittal pin had the maximum pin spread at the fracture site, which the highest construct stiffness in extension, valgus, and external rotation loads. Skaggs recommended that both divergent and parallel coronal pins should be maximally separated at the fracture site for maximal stability [26]. Sankar suggested that loss of reduction occurs when the pin spread is less than $2 \mathrm{~mm}$ at the fracture site level [20]. Kocher divided the distal humerus into medial, central, and lateral columns. Then, it suggested that the divergent configuration should provide adequate spread between pins and engage both the lateral and central columns of the distal humerus [21]. Pennock conducted a retrospective review and suggested the pins should be spread at least $13 \mathrm{~mm}$ or more than one-third of humeral width at the fracture site to minimize the loss of reduction [32].

The third area is the weakness of the parallel sagittal pin configuration under extension loads despite the fact that it carried significantly high construct stiffness in external rotation loading as divergent sagittal pin configuration. Lee studied the biomechanics of construct stiffness between divergent and parallel pin configurations in the coronal plane [17]. His results showed significantly lower construct stiffness with the parallel compared to divergent pinning. That explains the "lock" and "unlock" effect of the angle between the two pins, which concurs with our finding that with the divergent sagittal pin configuration, the two pins act together to create a "lock" effect, while parallel pins create an "unlock" effect under extension load.

There were some limitations to our study. The first and most important limitation was the limited number of specimens $(n=3)$ used for each loading test. According to the power analysis, our study would require at least eight specimens in each loading test to achieve $80 \%$ power to detect a significantly large effect size (Cohen's d 2.0) accounting for multiplicity. Thus, our results might be considered only for hypothesis-generating. Further research with an adequate study size is still needed to confirm our findings. Second, the material used was not an authentic human bone. Thus, it lacks natural pediatric bone properties such as soft tissue tensioning, periosteal effect, and cartilaginous physis. Pediatrics cadavers are very rare and are more expensive than artificial bone. However, a synthetic model does have advantages, e.g., the realistic anatomy truly represents the limitations of pin placement in pediatric bone, the specimens are homogeneous, and the results are reproducible. Real pediatric human bone varies in bone quality, bone density, and periosteal thickening, confounding factors avoided by using the pediatric synthetic bone.

\section{Conclusions}

For the fixation of pediatrics supracondylar fractures with controlled divergent lateral entry coronal pin configuration, the divergent sagittal pin configuration is recommended as it provides the highest construct stiffness under various loads compared to other sagittal pin configurations. The superiority of the divergent sagittal pin configuration could be explained by the maximal pin spreading distance at the fracture site and the pin angle lock mechanism. 
Author Contributions: Conceptualization, W.P., Y.S., and D.P.; methodology, W.P., K.N., and D.P.; software, W.P., P.P., and K.N.; validation P.P. and D.P.; formal analysis, W.P. and P.P.; investigation, W.P., K.N., N.W., and C.S.; resources, D.P.; data curation, W.P.; writing-original draft preparation, W.P. and Y.S.; writing-review and editing, P.P. and D.P.; visualization, W.P.; supervision, D.P.; project administration, D.P.; funding acquisition, D.P. All authors have read and agreed to the published version of the manuscript.

Funding: This research received no external funding.

Institutional Review Board Statement: The research ethics committee of the Faculty of Medicine, Chiang Mai University, approved the study protocol (ORT 2562 06622).

Informed Consent Statement: Not Applicable.

Data Availability Statement: The datasets used and/or analyzed during the current study are available from the corresponding author on reasonable request.

Acknowledgments: We would like to express our sincere thanks to G Lamar Robert and Chongchit Sripun Robert for English editing the manuscript, and Areerak Phanphaisarn for her useful and encouraging supports during the research and publication process. This work was partially supported by the Faculty of Medicine, Chiang Mai University.

Conflicts of Interest: The authors declare no conflict of interest.

\section{References}

1. Farnsworth, C.L.; Silva, P.D.; Mubarak, S.J. Etiology of Supracondylar Humerus Fractures. J. Pediatr. Orthop. 1998, 18, 38-42. [CrossRef] [PubMed]

2. Swenson, A.L. The Treatment of Supracondylar Fractures of the Humerus by Kirschner-Wire Transfixion. J. Bone Jt. Surg. Am. 1948, 30A, 993-997. [CrossRef]

3. Omid, R.; Choi, P.D.; Skaggs, D.L. Supracondylar Humeral Fractures in Children. J. Bone Jt. Surg. Am. 2008, 90, 1121-1132. [CrossRef]

4. Ym, Y.; Ms, K. Lateral Entry Compared with Medial and Lateral Entry Pin Fixation for Completely Displaced Supracondylar Humeral Fractures in Children. Surgical Technique. J. Bone Jt. Surg. Am. 2008, 90 Pt 1 (Suppl. 2), 20-30. [CrossRef]

5. Leitch, K.K.; Kay, R.M.; Femino, J.D.; Tolo, V.T.; Storer, S.K.; Skaggs, D.L. Treatment of Multidirectionally Unstable Supracondylar Humeral Fractures in Children. A Modified Gartland Type-IV Fracture. J. Bone Jt. Surg. Am. 2006, 88, 980-985. [CrossRef]

6. Skaggs, D.L. Elbow Fractures in Children: Diagnosis and Management. J. Am. Acad. Orthop. Surg. 1997, 5, 303-312. [CrossRef]

7. Topping, R.E.; Blanco, J.S.; Davis, T.J. Clinical Evaluation of Crossed-Pin versus Lateral-Pin Fixation in Displaced Supracondylar Humerus Fractures. J. Pediatr. Orthop. 1995, 15, 435-439. [CrossRef]

8. Nacht, J.L.; Ecker, M.L.; Chung, S.M.; Lotke, P.A.; Das, M. Supracondylar Fractures of the Humerus in Children Treated by Closed Reduction and Percutaneous Pinning. Clin. Orthop. 1983, 203-209. [CrossRef]

9. Flynn, J.C.; Matthews, J.G.; Benoit, R.L. Blind Pinning of Displaced Supracondylar Fractures of the Humerus in Children. Sixteen Years' Experience with Long-Term Follow-Up. J. Bone Jt. Surg. Am. 1974, 56, 263-272. [CrossRef]

10. Mehserle, W.L.; Meehan, P.L. Treatment of the Displaced Supracondylar Fracture of the Humerus (Type III) with Closed Reduction and Percutaneous Cross-Pin Fixation. J. Pediatr. Orthop. 1991, 11, 705-711. [CrossRef] [PubMed]

11. Mehlman, C.T.; Crawford, A.H.; McMillion, T.L.; Roy, D.R. Operative Treatment of Supracondylar Fractures of the Humerus in Children: The Cincinnati Experience. Acta Orthop. Belg. 1996, 62 (Suppl. 1), 41-50.

12. Cheng, J.C.; Lam, T.P.; Shen, W.Y. Closed Reduction and Percutaneous Pinning for Type III Displaced Supracondylar Fractures of the Humerus in Children. J. Orthop. Trauma 1995, 9, 511-515. [CrossRef]

13. Foead, A.; Penafort, R.; Saw, A.; Sengupta, S. Comparison of Two Methods of Percutaneous Pin Fixation in Displaced Supracondylar Fractures of the Humerus in Children. J. Orthop. Surg. Hong Kong 2004, 12, 76-82. [CrossRef]

14. Mazda, K.; Boggione, C.; Fitoussi, F.; Penneçot, G.F. Systematic Pinning of Displaced Extension-Type Supracondylar Fractures of the Humerus in Children. A Prospective Study of 116 Consecutive Patients. J. Bone Jt. Surg. Br. 2001, 83, 888-893. [CrossRef]

15. Herzenberg, J.E.; Koreska, J.; Carroll, N.C.; Rang, M. Biomechanical Testing of Pin Fixation Techniques for Pediatric Supracondylar Elbow Fractures. Orthop. Trans. 1988, 12, 678-679.

16. Larson, L.; Firoozbakhsh, K.; Passarelli, R.; Bosch, P. Biomechanical Analysis of Pinning Techniques for Pediatric Supracondylar Humerus Fractures. J. Pediatr. Orthop. 2006, 26, 573-578. [CrossRef] [PubMed]

17. Lee, S.S.; Mahar, A.T.; Miesen, D.; Newton, P.O. Displaced Pediatric Supracondylar Humerus Fractures: Biomechanical Analysis of Percutaneous Pinning Techniques. J. Pediatr. Orthop. 2002, 22, 440-443. [CrossRef] [PubMed]

18. Zionts, L.E.; McKellop, H.A.; Hathaway, R. Torsional Strength of Pin Configurations Used to Fix Supracondylar Fractures of the Humerus in Children. J. Bone Jt. Surg. Am. 1994, 76, 253-256. [CrossRef] 
19. Gaston, R.G.; Cates, T.B.; Devito, D.; Schmitz, M.; Schrader, T.; Busch, M.; Fabregas, J.; Rosenberg, E.; Blanco, J. Medial and Lateral Pin versus Lateral-Entry Pin Fixation for Type 3 Supracondylar Fractures in Children: A Prospective, Surgeon-Randomized Study. J. Pediatr. Orthop. 2010, 30, 799-806. [CrossRef]

20. Sankar, W.N.; Hebela, N.M.; Skaggs, D.L.; Flynn, J.M. Loss of Pin Fixation in Displaced Supracondylar Humeral Fractures in Children: Causes and Prevention. J. Bone Jt. Surg. Am. 2007, 89, 713-717. [CrossRef]

21. Kocher, M.S.; Kasser, J.R.; Waters, P.M.; Bae, D.; Snyder, B.D.; Hresko, M.T.; Hedequist, D.; Karlin, L.; Kim, Y.-J.; Murray, M.M.; et al. Lateral Entry Compared with Medial and Lateral Entry Pin Fixation for Completely Displaced Supracondylar Humeral Fractures in Children. A Randomized Clinical Trial. J. Bone Jt. Surg. Am. 2007, 89, 706-712. [CrossRef]

22. Woratanarat, P.; Angsanuntsukh, C.; Rattanasiri, S.; Attia, J.; Woratanarat, T.; Thakkinstian, A. Meta-Analysis of Pinning in Supracondylar Fracture of the Humerus in Children. J. Orthop. Trauma 2012, 26, 48-53. [CrossRef] [PubMed]

23. Lyons, J.P.; Ashley, E.; Hoffer, M.M. Ulnar Nerve Palsies after Percutaneous Cross-Pinning of Supracondylar Fractures in Children's Elbows. J. Pediatr. Orthop. 1998, 18, 43-45. [CrossRef]

24. Ariño, V.L.; Lluch, E.E.; Ramirez, A.M.; Ferrer, J.; Rodriguez, L.; Baixauli, F. Percutaneous Fixation of Supracondylar Fractures of the Humerus in Children. J. Bone Jt. Surg. Am. 1977, 59, 914-916. [CrossRef]

25. Kallio, P.E.; Foster, B.K.; Paterson, D.C. Difficult Supracondylar Elbow Fractures in Children: Analysis of Percutaneous Pinning Technique. J. Pediatr. Orthop. 1992, 12, 11-15. [CrossRef]

26. Skaggs, D.L.; Cluck, M.W.; Mostofi, A.; Flynn, J.M.; Kay, R.M. Lateral-Entry Pin Fixation in the Management of Supracondylar Fractures in Children. J. Bone Jt. Surg. Am. 2004, 86, 702-707. [CrossRef] [PubMed]

27. Wallace, M.; Johnson, D.B.; Pierce, W.; Iobst, C.; Riccio, A.; Wimberly, R.L. Biomechanical Assessment of Torsional Stiffness in a Supracondylar Humerus Fracture Model. J. Pediatr. Orthop. 2019, 39, e210-e215. [CrossRef]

28. Jaeblon, T.; Anthony, S.; Ogden, A.; Andary, J.J. Pediatric Supracondylar Fractures: Variation in Fracture Patterns and the Biomechanical Effects of Pin Configuration. J. Pediatr. Orthop. 2016, 36, 787-792. [CrossRef]

29. Hamdi, A.; Poitras, P.; Louati, H.; Dagenais, S.; Masquijo, J.J.; Kontio, K. Biomechanical Analysis of Lateral Pin Placements for Pediatric Supracondylar Humerus Fractures. J. Pediatr. Orthop. 2010, 30, 135-139. [CrossRef]

30. Otsuka, N.Y.; Kasser, J.R. Supracondylar Fractures of the Humerus in Children. J. Am. Acad. Orthop. Surg. 1997, 5, 19-26. [CrossRef]

31. Skaggs, D.L.; Hale, J.M.; Bassett, J.; Kaminsky, C.; Kay, R.M.; Tolo, V.T. Operative Treatment of Supracondylar Fractures of the Humerus in Children. The Consequences of Pin Placement. J. Bone Jt. Surg. Am. 2001, 83, 735-740. [CrossRef]

32. Pennock, A.T.; Charles, M.; Moor, M.; Bastrom, T.P.; Newton, P.O. Potential Causes of Loss of Reduction in Supracondylar Humerus Fractures. J. Pediatr. Orthop. 2014, 34, 691-697. [CrossRef] [PubMed] 